\title{
Oncogenic Human Papillomavirus: Application of CRISPR/Cas9 Therapeutic Strategies for Cervical Cancer
}

\author{
Shuai Zhen ${ }^{a, b, c} \quad X u L^{a, b}$ \\ aCenter for Translational Medicine, the First Affiliated Hospital of Xi'an Jiaotong University, Xi'an, ${ }^{b}$ Key \\ Laboratory for Tumor Precision Medicine of Shaanxi Province, the First Affiliated Hospital of Xi'an \\ Jiaotong University, Xi'an, 'Baoji Maternal and Child Health Hospital, WeiBin District, Baoji City, Shanxi, \\ China
}

\author{
Key Words \\ Hpv • Cervical cancer • CRISPR/Cas9
}

\begin{abstract}
Oncogenic human papillomaviruses (HPVs) cause different types of cancer especially cervical cancer. HPV-associated carcinogenesis provides a classical model system for clustered regularly interspaced short palindromic repeats (CRISPR/Cas9) based cancer therapies since the viral oncogenes E6 and E7 are exclusively expressed in cancerous cells. Sequence-specific gene knockdown/knockout using CRISPR/Cas9 shows promise as a novel therapeutic approach for the treatment of a variety of diseases that currently lack effective treatments. However, CRISPR/Cas9-based targeting therapy requires further validation of its efficacy in vitro and in vivo to eliminate the potential off-target effects, necessitates verification of the delivery vehicles and the combinatory use of conventional therapies with CRISPR/Cas9 to ensure the feasibility and safety. In this review we discuss the potential of combining CRISPR/Cas9 with other treatment options as therapies for oncogenic HPVs-associated carcinogenesis. and present our assessment of the promising path to the development of CRISPR/Cas9 therapeutic strategies for clinical settings.

\section{Introduction}

Human papillomaviruses (HPVs) are small DNA viruses with a genome size $\sim 8 \mathrm{~kb}$ long (Fig. 1). They infect cutaneous or mucosal epithelial cells, genital tissues, and the upper respiratory tract. To date, over 200 genetically distinct subtypes of HPV have been identified, and approximately 90 genotypes have been fully characterized. Among these types, the highrisk HPVs (HR-HPVs), including HPV-16, 18, 31, 33, 35, 39, 45, 51, 52, 56, 58, 59, 68, 73, and 82 , are associated with more than $90 \%$ of cervical cancers, and to a lesser extent with other anogenital cancers and head and neck cancers [1-4]. Over 50\% of HPV-positive cervical

Prof. Xu Li

KARGER
Center for Translational Medicine, Key Laboratory for Tumor Precision Medicine of Shaanxi Province, The First Affiliated Hospital, Xi'an Jiaotong University

277 West Yanta Road, Xi'an, Shaanxi 710061, (China); E-Mail lixu56@mail.xjtu.edu.cn 


\section{Cellular Physiology Cell Physiol Biochem 2017;44:2455-2466

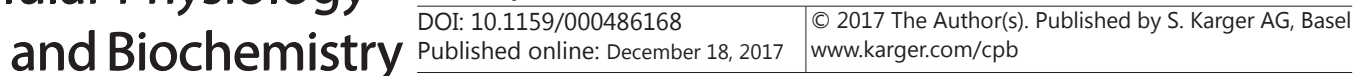

cancers are with HPV-16, followed by HPV-18 (12\%), HPV-45 (8\%), and HPV-31 (5\%) [5, 6]. Moreover, HPV16 is associated with a small number of head and neck neoplasia, particularly tonsillar and oro-pharyngeal cancers [7]. Low-risk HPVs (LR-HPVs), including HPV-6, $11,40,42,43,44,54,61,70,72$, and 81 , have been linked to benign epithelial lesions [8]. In contrast to HR-HPV, infections with low-risk HPVs(LR-HPV) types 6 and 11 are associated with genital warts, essentially laryngeal papilloma, and recurrent respiratory papillomatosis [9].

The HPV genome is composed of an early region (E) that encodes open reading frames involved in the regulation of viral replication and the viral life cycle, and a late region (L) that encodes two ORFs (L1 and

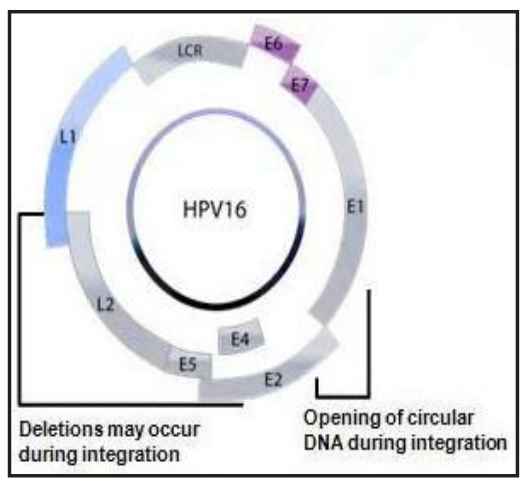

Fig. 1. Genome of HPV virus. L2) that form the viral capsid. During the course of HR-HPV-mediated cancer development, the viral DNAs are frequently integrated into host cell chromosomes, and the proteins encoded by the viral genes play a critical role in carcinogenesis. When infecting host, most HPV are cleared within months, but some HPVs persistently exist and viral oncogenes constantly express to inactivate p53 and Rb, leading to increased genomic instability, accumulation of somatic mutations, and in some cases integration of HPV into the host genome [10,11].

\section{HR-HPV and Cervical cancer}

Cervical cancer is one of the most common types of gynecological malignancies worldwide. According to the World Health Organization, the global prevalence of HPV infections was approximately 630 million cases in 2012, and 190 million cases were clinical infections leading to 528, 000 new diagnoses of cervical carcinoma and $~ 266,000$ deaths [12]. Advances in research continue to improve the precautionary methods available in developed countries. Clinical and molecular epidemiological studies have clearly demonstrated that the major cause of cervical cancer is infection with HR-HPVs, such as types 16 and 18. Strength of the association: The strength of association between HR-HPV and cervical cancer is considered one of the strongest for a human cancer. Recent studies have shown that HPV (all types combined) is present in $>95 \%$ of cervical cancers. Consistency: The presence of HRHPV in cervical cancer is consistent among a large number of studies, regardless which kind of HPV testing systems being used. There are no published studies with negative observations that challenge the association of HR-HPV and cervical cancer. Specificity: HR-HPVs are related to specific cancers. The type of HPVs is important in the development of specific cancers, such as cervical and head and neck cancers. HR-HPVs are present in the tumor cells. Viral oncogene expression (E6 and E7) occurs in tumor cells, but not in stromal cells. Temporality: HR-HPVs infections precede pre-cancerous cervical lesions and cervical cancer by years to decades. Biological gradient: Unclear, but early studies show that cervical cancer is associated with high viral loads [10-12]. Biological plausibility: HR-HPVs are powerful carcinogens that immortalizes human keratinocytes in vitro. HR-HPVs are present in cervical cancer, where they express the oncogenic proteins E6 and E7 to inactivate the host regulatory proteins p53 and RB, respectively. Epidemiological studies support a role for HR-HPV in cervical cancer. Biological coherence: The association does not conflict with what is known about the natural history of cervical cancer development. Experimental evidence: In vitro and in vivo evidence supports a causal role for HR-HPV in the development of cervical cancer. Analogy: Other DNA viruses can induce cancers in humans, and species-specific papilloma viruses can induce cancers in animals.Although early cervical cancer can be treated with surgery or radiation, metastatic cervical cancer is incurable and new therapeutic approaches are urgently needed. While most HPV infections are cleared within months, some infection persist and 


\section{Cellular Physiology Cell Physiol Biochem 2017;44:2455-2466

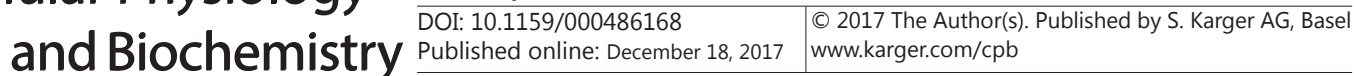 \\ Zhen/Li: Application of CRISPR/Cas9 for Cervical Cancer}

viral oncogenes constantly express to inactivate $\mathrm{p} 53$ and $\mathrm{Rb}$, leading to increased genomic instability, accumulation of somatic mutations, and in some cases integration of HPV into the host genome $[10,11]$.

\section{The role of $\mathrm{E} 6$ and $\mathrm{E} 7$ in carcinogenesis (Fig. 2)}

The HPV E6 protein is a $\sim 150$ amino acids-length basic polypeptide

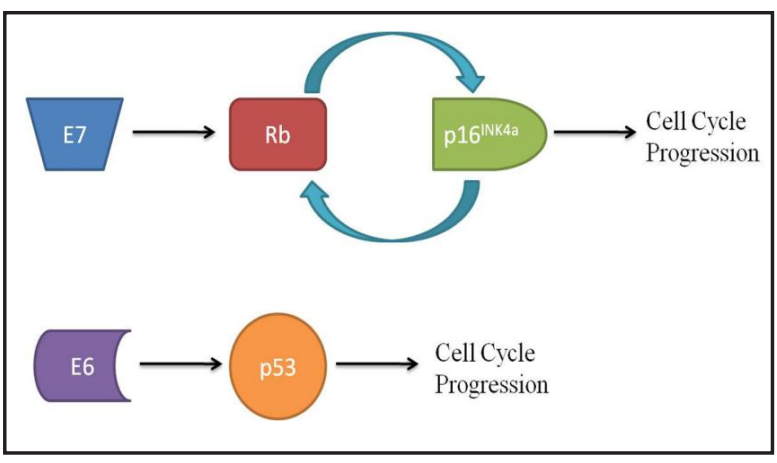

Fig. 2. Oncogenic pathways of E6 and E7. containing two zinc-finger motifs [13], each consisting of a CXXC-X29-CXXC sequence and the PDZ-binding epitope at C-terminal $[14,15]$. The expression regulation of E6 can be achieved through splice donor sites that give rise to truncated forms of E6, denoted as $\mathrm{E} 6^{*} \mathrm{I} \sim \mathrm{IV}$, dependent upon the position of the downstream splice acceptors [1619]. The most abundant splice RNA, E6*I, actually function as an E6 mRNA for efficient E6 translation [20-22]. The HR-HPV E6 protein and the truncated E6*I peptide destabilize several host proteins involved in cell growth and differentiation $[19,23]$. Oncogenic HPV infection also deregulates the expression of oncogenic and tumor suppressive miRNAs via E6-TP53 pathways $[24,25]$.

E6 oncogene is expressed after viral integration. E6 protein facilitates several cellular changes to prolong the cellular lifespan by blocking apoptosis and increasing telomerase activity. The transcriptional activator role of E6 may be coupled with its ability to immortalize and transform cells [26]. E6 binds to cellular proteins, particularly to the HECT domain of ubiquitin ligase E3A [UBE3A, also known as E6-associated protein (E6AP)], and to E6BP (reticulocalbin 2, an EF-hand calcium-binding domain). UBE3A interacts with HPV E6 at a conserved LXXLL motif and forms ternary complexes with TP53, resulting in TP53 degradation through ubiquitin-dependent mechanisms [27-29]. Moreover, E6 can block the translocation of TP53 into the nucleus [30] and thereby inhibit the gene expression regulatory functions of TP53. The promotion of TP53 degradation and block of TP53 transportation into the nucleus by E6 disrupt TP53-mediated cell cycle control, allowing continued cell division despite DNA damage. In previous studies, the results demonstrated that expression of the HPV16 E6* isoform increases oxidative stress and induces oxidative DNA damage in host cells [31, 32]. HR-HPV E6 can also impair apoptosis by accelerating degradation of Bak, c-Myc, FADD, and procaspase-8. Furthermore, E6 binds to E6TP1, hADA3, tuberin, CBP/p300, and Gps2, interfering with the function of these proteins to finally stimulate cell proliferation. E6 also suppresses the innate immune system through binding to IRF-3, as well as downregulating TLR9 expression [33]. Also oncogenic HPV E6 is capable of regulating the expression of many cellular miRNAs like miR-34a [34].

E7 ORF encodes an acidic phosphoprotein with zinc-binding motifs consisting of CXXCX29-CXXC [35] that is essential for proper protein folding and stability. The E7 protein is primarily localized in the nucleus, capable of inducing cellular proliferation, immortalization, and transformation [36]. HR-HPV E7 confers transforming activities and therefore immortalizes human keratinocytes via interacting with factors involved in the regulation of cell growth [37]. Most E7 proteins contain a strictly conserved LXCXE-binding motif that interacts with members of the RB family of tumor suppressors, resulting in ubiquitinmediated degradation of the RB family members [38]. Binding of E7 to hyper-phosphorylated $\mathrm{RB}(\mathrm{pRB}$ ) results in the release of the E2F transcription factor, activating gene transcription [39]. E7 from both HR and LR-HPVs possesses the ability to bind to pRB, although the interaction between LR-HPVs E7 and pRB is much weaker [40]. Furthermore, HR-HPV E7 interacts with and upregulate expression of cyclins $A$ and $\mathrm{E}$, inactivates the cyclin-dependent 


\section{Cellular Physiology Cell Physiol Biochem 2017;44:2455-2466

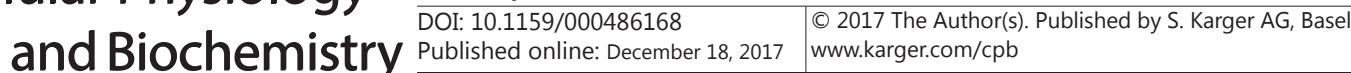 \\ Zhen/Li: Application of CRISPR/Cas9 for Cervical Cancer}

kinase (CDK) inhibitors CDKN1A (p21CIP1) and CDKN1B (p27KIP1), finally promotes cell cycle progression [41]. HPV-16 E7 protein can modulate the cytoplasmic localization of CDKN1B (p27KIP1) and in turn regulate tumor metastasis/aggressiveness through the PI3K/AKT pathway [42].

\section{Therapeutics against HPVs}

In 2006, the US Food and Drug Administration (FDA) approved Gardasil to be used in girls and women for the prevention of cervical, vaginal, and anal cancers and genital warts. In 2009, FDA approved it to be used in boys and men to prevent anal cancers and genital warts. In 2014, a new 9-valent HPV vaccine was approved. However, current vaccines are not evidently effective for the therapy of cervical cancer patients [43, 44].

For cervical cancer therapy, E6 or the E6/UBE3A complex deserve special attention as specific targets. Several strategies targeting E6 or the E6/E6-AP complex have been developed, exemplified by cytotoxic drugs, a zinc-ejecting inhibitor of the viral E6 oncoprotein, an E6AP mimetic epitope peptide (mimotope), an anti-E6 ribozyme, peptide aptamers targeting the viral E6 oncoprotein, siRNAs of the viral E6 oncogene, and combinations of all these therapies [45-53]. A new strategy is to induce viral E6 and E7 instability by using HSP90 and GRP78 inhibitors for the treatment of cervical cancer [54]. An E7 antagonist peptide reactivating $\mathrm{pRB}$ in vitro and in vivo shows antitumor effects [55]. GS-9191, a nucleotide analog prodrug, shows the anti-proliferative effect in vitro, and its topical application reduces the size of papilloma in the cottontail rabbit papillomavirus model [56]. Chitosan hydrogel containing granulocyte-macrophage colony-stimulating factor (GM-CSF) in combination with anticancer drugs, cyclophosphamide in particular, results in antitumor effects through CD8+ T cell immunity [57]. Heparin-like glycosaminoglycans inhibit tumor growth by downregulating HPV18 long control region activity in transgenic mice [58]. Finally, 5-aza2 '-deoxycytidine, a demethylating agent, and 5, 6-dimethyl xanthenone-4-acetic acid, a vascular disrupting agent, have each been combined with therapeutic HPV DNA vaccines $[59,60]$, showing significant antitumor therapeutic effects in vivo.

Additionally, antiviral RNAi therapies have been developed and tested in clinical trials with short interfering RNAs (siRNAs) [61]. siRNAs have been demonstrated to be capable of selective silencing of endogenous genes in mammalian cells $[62,63]$, and of selectively silencing viral genes in virus-induced diseases [64-66]. Remarkably, it has been reported that siRNA targeting E7 or E6/E7 promotes the accumulation of TP53 and/or pRB, eventually leading to the induction of apoptosis and/or senescence in HPV16-positive cervical cancer cell lines [67, 68], as well as in HPV18-positive human cervical cancer cells [69, 70]. It has been reported earlier that, silencing of both E6 and E7 produces greater anticancer activity than silencing E6 alone [71-73].

Recently, CRISPR/Cas9 has been developed as a novel therapeutic strategy and has entered into clinical trials. The difference between RNAi and CRISPR/Cas9 is shown in Table 1. The therapeutic mechanism of CRISPR/Cas9-mediated silencing of both E6 and E7 mainly depends on the reactivation of TP53 and pRB to induce apoptosis and cellular senescence.

Table 1. Comparisons between RNAi, CRISPR centric technologies

\begin{tabular}{lcc}
\hline & RNAi & CRISPR/Cas9 \\
\hline $\begin{array}{l}\text { Loss-of-function mechanism } \\
\text { Result }\end{array}$ & Post-transcriptional RNA degradation & Frame shift DNA mutation \\
Transgenes & Reversible knockdown & Permanent knockout \\
Guiding sequence & si/shRNA & Cas9 nuclease \\
Required sequence information & si/shRNA & gRNA \\
Off-target space & Transcriptome \\
Transcript variants & Transcriptome & Transcriptome \\
\hline
\end{tabular}


Yu et al. [74] have reported a CRISPR/Cas9 sequence targeting the E6 mRNA reduces the level of full-length E6 mRNA and increases the level of TP53 protein. Hu et al. [75] also suggested that CRISPR/Cas9 inhibition of E7 as a potential therapeutic intervention for the treatment of cervical cancer.

Our study [76] has recently reported that CRISPR/Cas9 targeting the promoter and ORF of E6/E7 transcripts reduces E6 and E7 mRNA level, increases TP53 protein levels, decreases RB protein level, promotes apoptosis and inhibits growth of SiHa cells. Similarly, CRISPR/ Cas9 transfected cells exhibits mitigated growth in vivo. Kennedy et al. [77] have designed CRISPR/Cas9 that specifically targeted E6/E7 mRNA of HPV16 or HPV18. Its intratumoral administration has resulted in the inhibition of tumor growth and induction of apoptosis in vivo, promising CRISPR/Cas9 as a potential adjuvant therapy for cervical cancer.

\section{CRISPR/Cas9 technology: molecular tool for gene therapy}

Clustered regularly interspaced short palindromic repeats (CRISPR) and their associated proteins (cas proteins) form an adaptive immune system in most bacteria and archaea to target and inactivate invading phages, plasmids and other genetic elements [78-80]. There are three types of CRISPR systems (I, II, III), among which the type II CRISPR system from Streptococcus pyogenes has received the most attention and been summarized below.

In the CRISPR/Cas9 system, sgRNA directs Cas9 DNA endonuclease to the target DNA sequence next to the protospacer adjacent motif(PAM) for site-specific cleavage and produces sequence-specific double-strand breaks (DSBs) [81] (Fig. 3). Consequently, various mutations such as substitutions, deletions and insertions in the target genome are introduced by the host DNA repair machinery [82] including nonhomologous end joining (NHEJ) at the binding site [83] or homologous-dependent repair (HDR) [84]. Designs of sgRNAs for intended genes are flexible to cleave virtually any DNA sequence by simply designing a single RNA sequence that matches the targeted DNA [85]. In addition, because the sgRNA component is physically separate from Cas9 expression, the sgRNA is easily "programmed", with the possibility of many sgRNAs targeting multiple DNA sites to be expressed simultaneously with the same Cas9 [86]. Therefore, CRISPR/Cas9 has shown great promise in realizing potent and multiplex genome editing and regulation of gene expression without host dependence (Table 1). CRISPR/Cas9-based tools have been successfully applied in diverse organisms and in a broad range of research fields, including high throughput genetic screens [87-89], generation of gene knockouts in several species [90], and targeting of pathogens to eradicate infections such as HPV, HIV and HBV $[76,91,92]$. In our previous study, Cas9 has been used with cognate gRNAs to disrupt the HPV E6 and E7 coding sequences in $\mathrm{SiHa}$ cervical cancer cells that retains integrated HPV16 , a subtype of HPV that has been associated with greater than $50 \%$ of cervical tumors. Forty-eight hours after transfection of plasmids encoding Cas9 and gRNAs, viral transcript levels

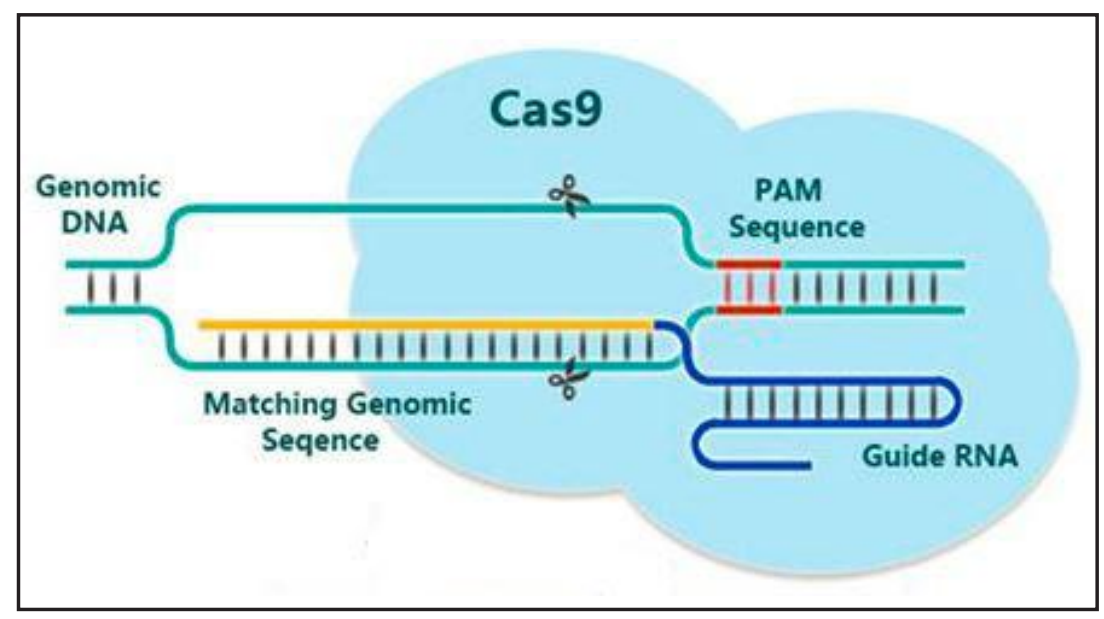

Fig. 3. The mechanism of CRISPR/Cas9 system. 


\section{Cellular Physiology Cell Physiol Biochem 2017;44:2455-2466

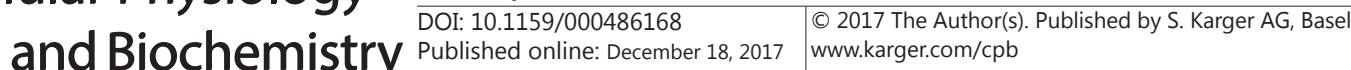 \\ Zhen/Li: Application of CRISPR/Cas9 for Cervical Cancer}

were reduced over $90 \%$ relative to cells transfected with control vectors. The reduction in E6 and E7 transcript levels correlated with an increase in host p53 and p21 (a cyclin-dependent kinase inhibitor used as a readout for $\mathrm{Rb}$ ) production, as well as a significant reduction in cell viability. Our another study has also demonstrated that both HBV cccDNA is susceptible to Cas9-mediated cleavage in cell culture as well as in vivo. Ye et al. [92] have recently demonstrated that deletion of the $32 \mathrm{bp}$ region of the ccr5 gene with Cas9:gRNA complexes confers resistance to CCR5-tropic HIV-1 in monocytes and macrophages differentiated from induced pluripotent stem cells.

\section{CRISPR/Cas9-based combination therapeutics against HPV}

Several CRISPR/Cas9 studies have been used in human cancer cell lines to identify modulators of drug sensitivity [93-98]. These studies address whether combination therapy with CRISPR/Cas9 can significantly enhance the chemo/radio sensitivity of cancer cells or prevent chemo/radio resistance resulting from long-term low-dose chemo/radio therapy. From a clinical perspective, if the combined effect is equal to the sum of the effects of the individual modalities, the effect of the multiple modalities is additive. If the combined effect is greater than the predicted effect of the multiple individual modalities, the interaction is synergistic. The multiple modalities may also interact in an antagonistic fashion. Statistical analysis using the Chou-Talalay method must be applied to determine the synergistic, additive, or antagonistic effects of CRISPR/Cas9-based combination therapies.

In our study, we have validated the role of CRISPR/Cas9 targeting the HPV E6 and E7 oncogenes as a potential sensitizer to CDDP [99] and radiation therapy (unpublished data) for the treatment of cervical carcinoma. Thus, the combination of CRISPR/Cas 9 targeting E6 or E6/E7 with cytotoxic agents may have synergistic effects on the restoration of TP53 and/or pRB function, and may be a more effective therapeutic modality for the treatment of cervical cancer. Further studies are required to overcome all the key points mentioned above and to develop clinically applicable combination therapies based on CRISPR/Cas9. Most importantly, to establish proof-of-concept for CRISPR/Cas9-based combination therapeutics, the mechanism underlying the synergy between the treatments should be elucidated. The results of in vivo experiments have demonstrated that combination therapy is significantly superior to either modality. Moreover, assessments to verify the absence of off-target effects and minimal induction of interferon are a prerequisite for the clinical application of CRISPR/ Cas9-based combination therapeutics.

\section{Conclusion and future perspective}

In spite of recent progress and various treatment modalities that have been proved beneficial to some extent, no effective treatment is currently available for HPV-associated carcinogenesis. Even though the precise molecular targets have been characterized and several approaches for their inhibition have been demonstrated, not currently possessing an effective treatment approach constitutes a problem as important as finding novel methods for the known targets and mechanisms. Nevertheless, the use of combinatorial treatment approaches with CRISPR/Cas9 appears to be best suited for clinical protocols. Since its discovery, CRISPR/Cas9 has enabled interrogation of the role of individual genes in complex cellular processes. Advancements in CRISPR/Cas9-based screening technologies have fueled the anticipation of new discoveries. However, CRISPR/Cas9-based therapeutics has encountered many barriers in clinical trials, including the potential off-target effect, optimization of target sites, in vivo safety and limited choice of delivery systems for treatment. For example, methods need to be optimized for efficient and safe delivery of the CRISPR/ Cas 9 components into the desired tissues. In the past 25 years, many clinical trials for gene therapy with conventional ectopic overexpression vectors have been conducted $[100,101]$. 


\section{Cellular Physiology Cell Physiol Biochem 2017;44:2455-2466 \begin{tabular}{l|l|l|}
\hline DOI: 10.1159/000486168 & $\begin{array}{l}\text { C) } 2017 \text { The Author(s). Published by S. Karger AG, Basel } \\
\text { www.karger.com/cpb }\end{array}$
\end{tabular} \\ Zhen/Li: Application of CRISPR/Cas9 for Cervical Cancer}

These studies provide promising results for gene delivery using both viral and non-viral vectors, which could potentially be adapted to deliver CRISPR/Cas9. Adeno-associated virus shuttle vectors seem particularly promising because of their high efficiency in transducing a broad range of cell types and their low cytotoxicity and immunogenicity. Another hurdle for applying CRISPR/Cas9 in patients is safety concerns resulting from the potential offtarget effects [102-107]. Two complementary strategies have been used in order to detect potential off-target sites: (1) biased methods that rely on bioinformatics algorithms to predict potential off-target sites and (2) unbiased methods that identify genome-wide DSBs generated by the SNs. Biased methods are, at the moment, unable to detect a large number of off-target sites and have become therefore a method to complement unbiased methods. Indeed, several unbiased technologies have been described (WGS, IDLV capture, GUIDE-seq, and LAM-HTGTS) that have shed light on the real specificity of several SNs, confirming some off-target sites predicted by bioinformatics algorithms and uncovering many more. All of these obstacles must be overcome if CRISPR/Cas9-based treatments for cancer are to be successful. CRISPR/Cas9 has the potential to become a reliable and facile genome editing tool after addressing the aforementioned issues. Benefiting from the simplicity and adaptability of CRISPR/Cas9, it opens the door for revealing gene function in biology and correcting gene defects seen in diseases. For instance, recent genome-wide deep sequencing results will be helpful for selecting suitable target sites and designing highly specific gRNA. In addition, associations and synergies between CRISPR/Cas9 and other chemo/radio therapeutic agents may open new avenues for treatment and improve the clinical outcome of patients with cervical cancer.

\section{Disclosure Statement}

The authors declare no conflicts of interest.

\section{Acknowledgements}

This study was supported by the National Natural Science Foundation of China (Grant No. 81602295 to Shuai Zhen).

\section{References}

1 Cogliano V, Baan R, Straif K, Grosse Y, Secretan B, El Ghissassi F: Carcinogenicity of human papillomaviruses. Lancet Oncol 2005;6:204.

-2 Munoz N, Bosch F X, de Sanjose S, Herrero R, Castellsague X, Shah K V, Snijders PJ, Meijer CJ: Epidemiologic classification of human papillomavirus types associated with cervical cancer. N Engl J Med 2003;348:518527.

3 zur Hausen H: Papillomaviruses in the causation of human cancers-A brief historical account. Virology 2009;384:260-265.

-4 de Villiers E.M, Fauquet C, Broker TR, Bernard HU, zur Hausen H: Classification of papillomaviruses. Virology 2004;324:17-27.

5 Scheffner M, Huibregtse JM, Vierstra RD, Howley PM: The HPV-16 E6 and E6-AP complex functions as a ubiquitin-protein ligase in the ubiquitination of p53. Cell 1993;75:495-505.

6 Munger K, Baldwin A, Edwards KM, Hayakawa H, Nguyen CL, Owens M, Grace M, Huh K: Mechanisms of human papillomavirus-induced oncogenesis. J Virol 2004;78:11451-11460.

7 Syrjanen S: The role of human papillomavirus infection in head and neck cancers. Ann Oncol 2010;21 Suppl 7:vii243-5.

8 Arbyn M, Castellsague X, de Sanjose S, Bruni L, Saraiya M, Bray F, Ferlay J: Worldwide burden of cervical cancer in 2008. Ann Oncol 2011;22:2675-2686. 


\section{Cellular Physiology Cell Physiol Biochem 2017;44:2455-2466

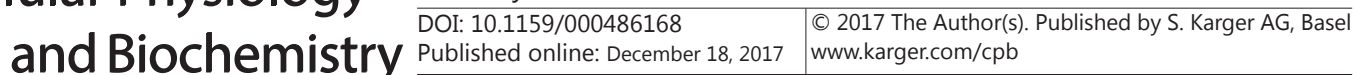 \\ Zhen/Li: Application of CRISPR/Cas9 for Cervical Cancer}

-9 Derkay CS, Wiatrak B: Recurrent respiratory papillomatosis by HPV: review of the literature and update on the use of cidofovir. Acta Otorhinolaryngol Ital 2014;34:375-81.

10 Cancer Genome AtlasResearchNetwork:Integrated genomic and molecular characterization of cervical cancer. Nature 2017;543:378-384.

-11 Cain JM, Howett MK: Preventing cervical cancer. Science. 2000;288:1753-1755.

12 Parkin DM, Bray F, Ferlay J, Pisani P: Global cancer statistics, 2002. CA Cancer J Clin 2005;55:74-108.

-13 Sherman L, Schlegel R: Serum- and calcium-induced differentiation of human keratinocytes is inhibited by the E6 oncoprotein of human papillomavirus type 16. J Virol 1996;70:3269-3279.

14 Kanda T, Watanabe S, Zanma S, Sato H, Furuno A, Yoshiike K: Human papillomavirus type 16 E6 proteins with glycine substitution for cysteine in the metal-binding motif. Virology 1991;185:536-543.

-15 Nomine Y, Masson M, Charbonnier S, Zanier K, Ristriani T, Deryckere F, Sibler AP, Desplancq D, Atkinson RA, Weiss E: Structural and functional analysis of E6 oncoprotein: Insights in the molecular pathways of human papillomavirus-mediated pathogenesis. Mol Cell 2006;21:665-678.

16 Dowhanick JJ, McBride AA, Howley PM: Suppression of cellular proliferation by the papillomavirus E2 protein. J Virol 1995;69:7791-7799.

17 Pett M, Coleman N: Integration of high-risk human papillomavirus: A key event in cervical carcinogenesis? J Pathol 2007;212:356-367.

18 Cornelissen MT, Smits HL, Briet MA, van den Tweel JG, Struyk AP, van der Noordaa J, ter Schegget J: Uniformity of the splicing pattern of the E6/E7 transcripts in human papillomavirus type 16-transformed human fibroblasts, human cervical premalignant lesions and carcinomas. J Gen Virol 1990;71:1243-1246.

19 Shirasawa H, Jin MH, Shimizu K, Akutsu N, Shino Y, Simizu B: Transcription-modulatory activity of fulllength E6 and E6*I proteins of human papillomavirus type 16. Virology 1994;203:36-42.

20 Tang S, Tao M, McCoy JP Jr, Zheng ZM: The E7 oncoprotein is translated from spliced E6*I transcripts in high-risk human papillomavirus type 16- or type 18-positive cervical cancer cell lines via translation reinitiation. J Virol 2006;80:4249-4263.

21 Ajiro M, Zheng ZM: Oncogenes and RNA splicing of human tumor viruses. Emerg Microbes Infec 2014;3:e63.

22 Ajiro M, Jia R, Zhang L, Liu X, Zheng ZM: Intron definition and a branch site adenosine at nt 385 control RNA splicing of HPV16 E6*I and E7 expression. Plos One 2012;7:e46412.

23 Pim D, Tomaic V, Banks L: The human papillomavirus (HPV) E6* proteins from high-risk, mucosal HPVs can direct degradation of cellular proteins in the absence of full-length E6 protein. J Virol 2009;83:98639874.

24 Zheng ZM, Wang X: Regulation of cellular miRNA expression by human papillomaviruses. Biochim Biophys Acta 2011;1809:668-677.

25 Wang X, Wang HK, Li Y, Hafner M, Banerjee NS, Tang S, Briskin D, Meyers C, Chow LT, Xie X, Tuschl T, Zheng ZM: MicroRNAs are biomarkers of oncogenic human papillomavirus infections. Proc Natl Acad Sci USA 2014;111:4262-4267.

26 Barbosa MS, Vass WC, Lowy DR, Schiller JT: In vitro biological activities of the E6 and E7 genes vary among human papillomaviruses of different oncogenic potential. J Virol 1991;65:292-298.

-27 Huibregtse JM, Scheffner M, Beaudenon S, Howley PM: A family of proteins structurally and functionally related to the E6-AP ubiquitin-protein ligase. Proc Natl Acad Sci USA 1995;92:2563-2567.

-28 Scheffner M, Werness BA, Huibregtse JM, Levine AJ, Howley PM: The E6 oncoprotein encoded by human papillomavirus types 16 and 18 promotes the degradation of p53. Cell 1990;63:1129-1136.

29 Schiffman M, Clifford G, Buonaguro FM: Classification of weakly carcinogenic human papillomavirus types: Addressing the limits of epidemiology at the borderline. Infect Agents Cancer 2009;4:8.

-30 Mantovani F, Banks L: Inhibition of e6 induced degradation of p53 is not sufficient for stabilization of p53 protein in cervical tumour derived cell lines. Oncogene 1991;18:3309-3315.

31 Williams VM, Filippova M, Filippov V, Payne KJ, Duerksen-Hughes P: Human papillomavirus type 16 E6* induces oxidative stress and DNA damage. J Virol 2014;88:6751-61.

-32 Chen Wongworawat Y, Filippova M, Williams VM, Filippov V, Duerksen-Hughes PJ: Chronic oxidative stress increases the integration frequency of foreign DNA and human papillomavirus 16 in human keratinocytes. Am J Cancer Res 2016;6:764-80.

-33 Tungteakkhun SS, Duerksen-Hughes PJ: Cellular binding partners of the human papillomavirus E6 protein. Arch. Virol 2008;153:397-408. 


\section{Cellular Physiology Cell Physiol Biochem 2017;44:2455-2466 \\ \begin{tabular}{l|l|l} 
and Biochemistry Published online: December 18, 2017 & $\begin{array}{l}\text { (c) } 2017 \text { The Author(s). Published by S. Karger AG, Basel } \\
\text { www.karger.com/cpb }\end{array}$
\end{tabular} \\ Zhen/Li: Application of CRISPR/Cas9 for Cervical Cancer}

34 Wang X, Wang HK, McCoy JP, Banerjee NS, Rader JS, Broker TR, Meyers C, Chow LT, Zheng ZM: Oncogenic HPV infection interrupts the expression of tumor-suppressive miR-34a through viral oncoprotein E6. RNA 2009;15:637-647.

35 Syrjanen S.M, Syrjanen KJ: New concepts on the role of human papillomavirus in cell cycle regulation. Ann. Med 1999;31:175-187.

-36 McMurray HR, Nguyen D, Westbrook TF, McAnce DJ: Biology of human papillomaviruses. Int J Exp Pathol 2001;82:15-33.

37 Halbert CL, Demers GW, Galloway DA: The E7 gene of human papillomavirus type 16 is sufficient for immortalization of human epithelial cells. J Virol 1991;65:473-478.

-38 Heck DV, Yee CL, Howley PM, Munger K: Efficiency of binding the retinoblastoma protein correlates with the transforming capacity of the E7 oncoproteins of the human papillomaviruses. Proc Natl Acad Sci USA 1992;89:4442-4446.

-39 McLaughlin-Drubin ME, Munger K: Oncogenic activities of human papillomaviruses. Virus Res 2009;143:195-208.

40 Longworth MS, Laimins LA: Pathogenesis of human papillomaviruses in differentiating epithelia. Microbiol Mol Biol Rev 2004;68:362-372.

41 Wang J, Sampath A, Raychaudhuri P, Bagchi S: Both Rb and E7 are regulated by the ubiquitin proteasome pathway in HPV-containing cervical tumor cells. Oncogene 2001;20:4740-4749.

42 Charette ST, McCance DJ: The E7 protein from human papillomavirus type 16 enhances keratinocyte migration in an AKT-dependent manner. Oncogene 2007;26:7386-7390.

43 Lowy DR, Schiller JT: Prophylactic human papillomavirus vaccines. J Clin Invest 2006;116:1167-1173.

44 Giuliano AR, Palefsky JM, Goldstone S, Moreira ED, Penny M.E, Aranda C, Vardas E, Moi H, Jessen H, Hillman R: Efficacy of quadrivalent HPV vaccine against HPV infection and disease in males. N Engl J Med 2011;364:401-411.

-45 Beerheide W, Bernard HU, Tan YJ, Ganesan A, Rice WG, Ting AE: Potential drugs against cervical cancer: Zinc-ejecting inhibitors of the human papillomavirus type 16 E6 oncoprotein J Natl Cancer Inst 1999;91:1211-1220.

-46 Beerheide W, Sim MM, Tan YJ, Bernard HU, Ting AE: Inactivation of the human papillomavirus-16 E6 oncoprotein by organic disulfides. Bioorganic Med Chem 2000;8:2549-2560.

47 Butz K, Denk C, Ullmann A, Scheffner M, Hoppe-Seyler F: Induction of apoptosis in human papillomaviruspositive cancer cells by peptide aptamers targeting the viral E6 oncoprotein. Proc Natl Acad Sci. USA 2000;97:6693-6697.

48 Butz K, Ristriani T, Hengstermann A, Denk C, Scheffner M, Hoppe-Seyler F: SiRNA targeting of the viral E6 oncogene efficiently kills human papillomavirus-positive cancer cells. Oncogene 2003;22:5938-5945.

49 Jiang M, Milner J: Selective silencing of viral gene expression in HPV-positive human cervical carcinoma cells treated with siRNA, a primer of RNA interference. Oncogene 2002;21:6041-6048.

50 Liu Y, Liu Z, Androphy E, Chen J, Baleja JD: Design and characterization of helical peptides that inhibit the E6 protein of papillomavirus. Biochemistry 2004;43:7421-7431.

-51 Wesierska-Gadek J, Schloffer D, Kotala V, Horky M: Escape of p53 protein from E6-mediated degradation in Hela cells after cisplatin therapy. Int J Cancer 2002;101:128-136.

52 Yoshinouchi M, Yamada T, Kizaki M, Fen J, Koseki T, Ikeda Y, Nishihara T, Yamato K: In vitro and in vivo growth suppression of human papillomavirus 16-positive cervical cancer cells by E6 siRNA. Mol Ther 2003;8:762-768.

53 Zheng YF, Rao ZG, Zhang JR: Effects of anti-HPV16 E6-ribozyme on the proliferation and apoptosis of human cervical cancer cell line CaSki. Di Yi Jun Yi Da Xue Xue Bao 2002;22:496-498.

54 Ajiro M, Zheng ZM: E6^ ${ }^{\wedge} 7$, a novel splice isoform protein of human papillomavirus 16, stabilizes viral E6 and E7 oncoproteins via HSP90 and GRP78. MBio 2014;6:02068-14

55 Guo CP, Liu KW, Luo HB, Chen HB, Zheng Y, Sun SN, Zhang Q, Huang L: Potent anti-tumor effect generated by a novel human papillomavirus (HPV) antagonist peptide reactivating the pRb/E2F pathway. Plos One 2011;6:e17734.

-56 Wolfgang GH, Shibata R, Wang J, Ray AS, Wu S, Doerrfler E, Reiser H, Lee WA, Birkus G, Christensen ND: Gs-9191 is a novel topical prodrug of the nucleotide analog 9-(2-phosphonylmethoxyethyl)guanine with antiproliferative activity and possible utility in the treatment of human papillomavirus lesions. Antimicrob. Agents Chemother 2009;53:2777-2784. 


\section{Cellular Physiology Cell Physiol Biochem 2017;44:2455-2466 \begin{tabular}{l|l|l} 
and Biochemistry Published 10.1159/000486168 & $\begin{array}{l}\text { C } 2017 \text { The Author(s). Published by S. Karger AG, Basel } \\
\text { www.karger.com/cpb }\end{array}$
\end{tabular} \\ Zhen/Li: Application of CRISPR/Cas9 for Cervical Cancer}

57 Seo SH, Han HD, Noh KH, Kim TW, Son SW: Chitosan hydrogel containing GMCSF and a cancer drug exerts synergistic anti-tumor effects via the induction of CD8+ T cell-mediated anti-tumor immunity. Clin Exp Metastasis 2009;26:179-187.

-58 Villanueva R, Morales-Peza N, Castelan-Sanchez I, Garcia-Villa E, Tapia R, Cid-Arregui A, Garcia-Carranca A, Lopez-Bayghen E, Gariglio P: Heparin (GAG-hed) inhibits LCR activity of human papillomavirus type 18 by decreasing AP1 binding. BMC Cancer 2006;6:218.

59 Peng S, Monie A, Pang X, Hung CF, Wu TC: Vascular disrupting agent DMXAA enhances the antitumor effects generated by therapeutic HPV DNA vaccines. J Biomed Sci 2011;18:21.

-60 Lu D, Hoory T, Monie A, Wu A, Wang MC, Hung CF: Treatment with demethylating agent, 5-aza-2' deoxycytidine enhances therapeutic hpv DNA vaccine potency. Vaccine 2009;27:4363-4369.

-61 Haasnoot J, Westerhout EM, Berkhout B: RNA interference against viruses: Strike and counterstrike. Nat Biotechnol 2007;25:1435-1443.

62 Sui G, Soohoo C, Affar el B, Gay F, Shi Y, Forrester WC: A DNA vector-based RNAi technology to suppress gene expression in mammalian cells. Proc Natl Acad Sci USA 2002;99:5515-5520.

63 Yu JY, DeRuiter SL, Turner DL: RNA interference by expression of short-interfering RNAs and hairpin RNAs in mammalian cells. Proc Natl Acad Sci USA 2002;99:6047-6052.

64 Ge Q McManus MT, Nguyen T, Shen CH, Sharp PA, Eisen HN, Chen J: RNA interference of influenza virus production by directly targeting mRNA for degradation and indirectly inhibiting all viral RNA transcription. Proc Natl Acad Sci USA 2003;100:2718-2723.

65 Kitabwalla M, Ruprecht RM: RNA interference-A new weapon against HIV and beyond. N Engl J Med 2002;347:1364-1367.

-66 Milner J:RNA interference for treating cancers caused by viral infection. Exp. Opin Biol Ther 2003;3:459467.

67 Sima N1, Wang W, Kong D, Deng D, Xu Q Zhou J, Xu G, Meng L, Lu Y, Wang S, Ma D: RNA interference against HPV16 E7 oncogene leads to viral E6 and E7 suppression in cervical cancer cells and apoptosis via upregulation of Rb and p53. Apoptosis 2008;13:273-281.

-68 Yamato K1, Yamada T, Kizaki M, Ui-Tei K, Natori Y, Fujino M, Nishihara T, Ikeda Y, Nasu Y, Saigo K, Yoshinouchi M: New highly potent and specific E6 and E7 siRNAs for treatment of HPV16 positive cervical cancer. Cancer Gene Ther 2008;15:140-153.

69 Gu W, Putral L, Hengst K, Minto K, Saunders NA, Leggatt G, McMillan NA: Inhibition of cervical cancer cell growth in vitro and in vivo with lentiviral-vector delivered short hairpin RNA targeting human papillomavirus E6 and E7 oncogenes. Cancer Gene Ther 2006;13:1023-1032.

70 Hall AH, Alexander KA: RNA interference of human papillomavirus type 18 E6 and E7 induces senescence in Hela cells. J Virol 2003;77:6066-6069.

71 Tang S1, Tao M, McCoy JP Jr, Zheng ZM: Short-term induction and long-term suppression of HPV16 oncogene silencing by RNA interference in cervical cancer cells. Oncogene 2006;25:2094-2104.

72 Zhou J, Peng C, Li B, Wang F, Zhou C, Hong D, Ye F, Cheng X, Lu W, Xie X: Transcriptional gene silencing of HPV16 E6/E7 induces growth inhibition via apoptosis in vitro and in vivo. Gynecol Oncol 2012;124:296302.

73 Jung HS, Erkin OC, Kwon MJ, Kim SH, Jung JI, Oh YK, Her SW, Ju W, Choi YL, Song SY: The synergistic therapeutic effect of cisplatin with human papillomavirus E6/E7 short interfering RNA on cervical cancer cell lines in vitro and in vivo. Int J Cancer 2012;130:1925-1936.

74 Yu L, Wang X, Zhu D, Ding W, Wang L, Zhang C, Jiang X, Shen H, Liao S, Ma D, Hu Z, Wang H: Disruption of human papillomavirus 16 E6 gene by clustered regularly interspaced short palindromic repeat/Cas system in human cervical cancer cells. Onco Targets Ther 2014;8:37-44.

75 Hu Z, Yu L, Zhu D, Ding W, Wang X, Zhang C, Wang L, Jiang X, Shen H, He D, Li K, Xi L, Ma D, Wang H: Disruption of HPV16-E7 by CRISPR/Cas system induces apoptosis and growth inhibition in HPV16 positive human cervical cancer cells. Biomed Res Int 2014;2014:612823.

76 Zhen S, Hua L, Takahashi Y, Narita S, Liu YH, Li Y: In vitro and in vivo growth suppression of human papillomavirus 16-positive cervical cancer cells by CRISPR/Cas9. Biochem Biophys Res Commun 2014;450:1422-6.

77 Kennedy EM, Kornepati AV, Goldstein M, Bogerd HP, Poling BC, Whisnant AW, Kastan MB, Cullen BR: Inactivation of the human papillomavirus E6 or E7 gene in cervical carcinoma cells by using a bacterial CRISPR/Cas RNA-guided endonuclease. J Virol 2014;88:11965-72. 


\section{Cellular Physiology Cell Physiol Biochem 2017;44:2455-2466 \\ \begin{tabular}{l|l|l} 
and Biochemistry Published online: December 18, 2017 & $\begin{array}{l}\text { (c) } 2017 \text { The Author(s). Published by S. Karger AG, Basel } \\
\text { www.karger.com/cpb }\end{array}$
\end{tabular} \\ Zhen/Li: Application of CRISPR/Cas9 for Cervical Cancer}

78 Hsu PD, Lander ES, Zhang F: Development and applications of CRISPR-Cas9 for genome engineering. Cell 2014;157:1262-1278.

79 Makarova KS, Wolf YI, Alkhnbashi OS, Costa F, Shah SA, Saunders SJ, Barrangou R, Brouns SJ, Charpentier E, Haft DH, Horvath P, Moineau S, Mojica FJ, Terns RM, Terns MP, White MF, Yakunin AF, Garrett RA, van der Oost J, Backofen R, Koonin EV: An updated evolutionary classification of CRISPR-Cas systems. Nat Rev Microbiol 2015;13:722-736.

-80 Wright AV, Nuñez JK, Doudna JA: Biology and Applications of CRISPR Systems: Harnessing Nature’s Toolbox for Genome Engineering. Cell 2016;164:29-44.

-81 van der Ploeg JR: Analysis of CRISPR in Streptococcus mutans suggests frequent occurrence of acquired immunity against infection by M102-like bacteriophages. Microbiology 2009;155:1966-1976

82 Wyman C, Kanaar R: DNA double-strand break repair: all's well that ends well. Annu Rev Genet 2006;40:363-383.

83 Matthews LA, Simmons LA: Bacterial nonhomologous end joining requires teamwork. J Bacteriol 2014;196:3363-3365.

84 Doudna JA, Charpentier E: Genome editing. The new frontier of genome engineering with CRISPR-Cas9. Science 2014;346:1258096.

85 Choi PS, Meyerson M: Targeted genomic rearrangements using CRISPR/Cas technology. Nat Commun 2014;5:3728.

-86 Cong L, Ran FA, Cox D, Lin S, Barretto R, Habib N, Hsu PD, Wu X, Jiang W, Marraffini LA, Zhang F: Multiplex genome engineering using CRISPR/Cas systems. Science 2013;339:819-823.

-87 Shalem O, Sanjana NE, Hartenian E, Shi X, Scott DA, Mikkelsen TS, Heckl D, Ebert BL, Root DE, Doench JG, Zhang F: Genome-scale CRISPR-Cas9 knockout screening in human cells. Science 2014;343:84-87.

-88 Bian S, Zhou Y, Hu Y, Cheng J, Chen X, Xu Y, Liu P: High-throughput in situ cell electroporation microsystem for parallel delivery of single guide RNAs into mammalian cells. Sci Rep 2017;13:42512.

-89 Rauscher B, Heigwer F, Breinig M, Winter J, Boutros M: Genome CRISPR - a database for high-throughput CRISPR/Cas9 screens. Nucleic Acids Res 2017;45:D679-D686

90 Bortesi L, Zhu C, Zischewski J, Perez L, Bassié L, Nadi R, Forni G, Lade SB, Soto E, Jin X, Medina V, Villorbina G, Muñoz P, Farré G, Fischer R, Twyman RM, Capell T, Christou P, Schillberg S: Patterns of CRISPR/Cas9 activity in plants, animals and microbes. Plant Biotechnol J 2016;14:2203-2216.

-91 Zhen S, Hua L, Liu YH, Gao LC, Fu J, Wan DY, Dong LH, Song HF, Gao X: Harnessing the clustered regularly interspaced short palindromic repeat (CRISPR)/CRISPR-associated Cas9 system to disrupt the hepatitis B virus. Gene Ther 2015;22:404-12.

\$2 Ye L, Wang J, Beyer AI, Teque F, Cradick TJ, Qi Z, Chang JC, Bao G, Muench MO, Yu J, Levy JA, Kan YW: Seamless modification of wild-type induced pluripotent stem cells to the natural CCR5Delta32 mutation confers resistance to HIV infection. Proc Natl Acad Sci USA 2014;111:9591-6.

93 Hesler RA, Huang JJ, Starr MD, Treboschi VM, Bernanke AG, Nixon AB, McCall SJ, White RR, Blobe GC: TGF- $\beta$-induced stromal CYR61 promotes resistance to gemcitabine in pancreatic ductal adenocarcinoma through downregulation of the nucleoside transporters hENT1 and hCNT3. Carcinogenesis 2016;37:10411051.

94 Dubey R, Lebensohn AM, Bahrami-Nejad Z, Marceau C, Champion M, Gevaert O, Sikic BI, Carette JE, Rohatgi R: Chromatin-Remodeling Complex SWI/SNF Controls Multidrug Resistance by Transcriptionally Regulating the Drug Efflux Pump ABCB1. Cancer Res 2016;76:5810-5821.

-95 Togashi Y, Mizuuchi H, Tomida S, Terashima M, Hayashi H, Nishio K, Mitsudomi T: MET gene exon 14 deletion created using the CRISPR/Cas9system enhances cellular growth and sensitivity to a MET inhibitor. Lung Cancer 2015;90:590-7.

-96 Kim JS, Cho DH, Park M, Chung WJ, Shin D, Ko KS, Kweon DH: CRISPR/Cas9-Mediated Re-Sensitization of Antibiotic-Resistant Escherichia coli Harboring Extended-Spectrum $\beta$-Lactamases. J Microbiol Biotechnol 2016;26:394-401.

97 Tsukamoto K, Ozeki C, Kohda T, Tsuji T: CRISPR/Cas9-Mediated Genomic Deletion of the Beta-1, 4 $\mathrm{N}$-acetylgalactosaminyltransferase 1 Gene in Murine P19 Embryonal Carcinoma Cells Results in Low Sensitivity to Botulinum Neurotoxin Type C. Plos One 2015;15:e0132363.

-98 Sugita S, Ito K, Yamashiro Y, Moriya S, Che XF, Yokoyama T, Hiramoto M, Miyazawa K: EGFR-independent autophagy induction with gefitinib and enhancement of its cytotoxic effect by targeting autophagy with clarithromycin in non-small cell lung cancer cells. Biochem Biophys Res Commun 2015;461:28-34. 


\section{Cellular Physiology Cell Physiol Biochem 2017;44:2455-2466 \begin{tabular}{l|l|l|} 
DOI: 10.1159/000486168 & $\begin{array}{l}\text { O 2017 The Author(s). Published by S. Karger AG, Basel } \\
\text { www.karger.com/cpb }\end{array}$ \\
\hline
\end{tabular} \\ Zhen/Li: Application of CRISPR/Cas9 for Cervical Cancer}

-99 Zhen S, Lu JJ, Wang LJ, Sun XM, Zhang JQ, Li X, Luo WJ, Zhao L: In vitro and In vivo Synergistic Therapeutic Effect of Cisplatin with Human Papillomavirus16 E6/E7 CRISPR/Cas9 on Cervical Cancer Cell Line. Transl Oncol 2016;9:498-504.

100 Mingozzi F, High KA: High Therapeutic in vivo gene transfer for genetic disease using AAV: progress and challenges. Nat Rev Genet 2011;12:341-355.

101 Kay MA: State-of-the-art gene-based therapies: the road ahead. Nat Rev Genet 2001;12:316-328

102 V Pattanayak, S.Lin, JP Guilinger, E Ma, JA Doudna, DR Liu: High-throughput profiling off-target DNA cleavage reveals RNA-programmed Cas9 nuclease specificity. Nat Biotechnol 2013;31:839-843.

-103 Fu Y, Foden JA, Khayter C, Maeder ML, Reyon D, Joung JK, Sander JD: High-frequency off-target mutagenesis induced by CRISPR-Cas nucleases in human cells. Nat Biotechnol 2013;31:822-826.

104 Lin Y, Cradick TJ, Brown MT, Deshmukh H, Ranjan P, Sarode N, Wile BM, Vertino PM, Stewart FJ, Bao G: CRISPR/Cas9 systems have off-target activity with insertions or deletions between target DNA and guide RNA sequences. Nucleic Acids Res 2014;42:7473-85.

105 Mandal PK, Ferreira LM, Collins R, Meissner TB, Boutwell CL, Friesen M, Vrbanac V, Garrison BS, Stortchevoi A, Bryder D, Musunuru K, Brand H, Tager AM, Allen TM, Talkowski ME, Rossi DJ, Cowan CA: Efficient ablation of genes in human hematopoietic stem and effector cells using CRISPR/Cas9. Cell Stem Cell 2014;15:643-52.

106 Cradick TJ, Fine EJ, Antico CJ, Bao G: CRISPR/Cas9 systems targeting $\beta$-globin and CCR5 genes have substantial off-target activity. Nucleic Acids Res2013;41:9584-92.

107 Cao J, Wu L, Zhang SM, Lu M, Cheung WK, Cai W, Gale M, Xu Q, Yan Q: An easy and efficient inducible CRISPR/Cas9 platform with improved specificity for multiple gene targeting. Nucleic Acids Res 2016;44:e149. 